\title{
French-English Cognates in the Jordanian Foreign Language Learning Classroom: Friends or Foes?
}

\author{
Samia Azieb ${ }^{1}$, Rajai AL-Khanji ${ }^{2} \&$ Majid Tarawneh ${ }^{3}$ \\ ${ }^{1}$ Department of English, Mohammed Seddik Benyahia University, Jijel, Algeria \\ ${ }^{2}$ Department of English, Jordan University, Amman, Jordan \\ ${ }^{3}$ Department of English, American University of Madaba, Madaba, Jordan \\ Correspondence: Samia Azieb, Department of English, Mohammed Seddik Benyahia University, Jijel, Algeria. \\ E-mail: aziebsamia@yahoo.com
}

Received: February 9, 2021

Accepted: March 12, 2021

Online Published: June 24, 2021

doi:10.5539/ies.v14n7p72

URL: https://doi.org/10.5539/ies.v14n7p72

\begin{abstract}
The aim of the present study is two-fold in essence. First, it aims at finding out the extent to which cognates' recognition aids Jordanian French-English bilinguals to translate from English into French. Second, it seeks to determine if such recognition can be a good strategy in learning foreign languages. Accordingly, a Translation Elicitation Task containing cognates and false cognates was devised and given to a sample of 31 students majoring in French at both the B.A and M.A levels at the University of Jordan. Findings of the study showed that most students did benefit from their English language background, and thus cognates facilitated their comprehension of French. However, some students participating in the translation test were not mindful of the lexical differences between English and French, thus producing an incorrect interpretation of the text. The study ends with a recommendation for foreign language instructors to teach cognate recognition strategies explicitly.
\end{abstract}

Keywords: cognates, false cognates, foreign language learning, Jordanian French-English bilinguals

\section{Introduction}

The main hallmark of languages is that they continuously evolve, change and share words. Therefore, there are some words that have a similar form and meaning in more than one language. These are known as "cognates". In fact, the latter have been a perennial theme of discussion amongst researchers for a long time. Such an interest in studying cognates stems, on the one hand, from the fact that many languages have cognates at their disposal and, on the other hand, from the fact that they are part and parcel of L2 learning in the sense that they help comprehension and acquisition. Accordingly, learning a word in a new language sometimes requires relating it to a similar word in another language.

Owing to the overriding importance of cognates, foreign language learners should take cognizance of their existence in the languages which they learn. This is because they can be used to their advantage in comprehending a new language. That is, they can be a source of positive transfer between languages as well as a strategy to aid in language acquisition by speeding up the process as a whole. In this regard, Lado (1957, pp. 1-2) maintained that" in the comparison between native and foreign language lies the key to ease or difficulty in foreign language learning... Those elements that are similar to [the learner's] native language will be simple for him and those elements that are different will be difficult. In other words, if no difference or contrast is present between two languages, the learner can simply transfer (positively) a sound, structure, or lexical item from the native language to the target language (Brown, 2007, p. 209). Examples of cognates include "university" and "université" in English and French, and "globalization" and "globalisierung" in English and German respectively.

Therefore, foreign language learners could benefit from the resemblances discovered in cognates and the knowledge between languages that belong to the same language family with the hope of accelerating lexicon acquisition. Intriguingly, teachers also need to resort to the use of cognates as a teaching tool in order to improve instruction and increase the learners' language proficiency.

Broaching the topic of the importance of cognates in second language learning necessitates giving heed first to the concept of "cognates". As a matter of fact, a multitude of definitions have been provided for it in the existing stockpile of literature. Accordingly, Walseth $(2013$, p. 1) is of the opinion that a cognate is simply "a word that has 
the same form and meaning in two or more languages". He further gives examples of the word democracy in English and democracia in Spanish, claiming that "a Spanish speaker learning English might be delighted to see the word 'democracy' and think that they have just learned a new word without actually having to put in any effort into understanding it since it is already stored in their lexicon". In a similar vein, Gholami, Alavinia, and Izadpanah (2015, p. 449) state that cognates can generally be elucidated as "words that combine features of orthography, phonology, and meaning beyond languages (e.g., Setereh in Persian and Star in English).

Moreover, in his definition of cognate words, Beltran (2006) stresses the shared origins as well as the semantic affinity between them: "cognate words in two or more languages have a common origin because of their diachronic relationship and as a result, they share some sort of formal and/or semantic affinity" (p. 29). Last but not least, Sunderman and Schwartz (2008, as cited in Burkholder, 2015, p. 1) consider cognates as "translation equivalents which share a substantial amount of form across the two languages" as in the case of translating the French word table /tabl/ into the English word table/tej.bl/.

At this juncture, it should be noted that there are L2 words which are formally similar to L1 words in spelling and/or pronunciation but whose meanings are totally or partially different in both languages (Talebinejad \& Sarmazeh, 2012). Such words are deceptive in nature and they are called false friends, false cognates, deceptive cognates, misleading cognates, or homographic non-cognates. Consider the following example in German and its translation in English:

German: Sie sind brav.

English: They are good.

Undeniably, brave in English means courageous while brav in German means good or well-behaved. Thus, false cognates are a real problem for language learners.

Apparently, English and French have a substantial number of lexical items that overlap in form and meaning due in part to their common Indo-European origin, and also to the fact that they have been in significant contact over the course of history. Therefore, obtaining further insights into the awareness of Jordanian learners of French about the existence of cognate words in English and French is a topic that merits investigation.

Based on the research objectives and considering the reviewed literature, the present study seeks to answer the following research questions:

1) Are Jordanian learners of French aware of the existence of cognates in English and French?

2) Does knowledge of cognates facilitate the process of learning French for Jordanian learners?

\section{Literature Review}

The cross-linguistic phenomenon of "cognates" and its role in facilitating the second language learning process have been an attention-grabbing destination for many researchers. Consequently, studies on them abound. To begin with, Moss (1992) analysed a corpus of approximately 1500 English/Spanish cognates which were obtained from articles chosen at random from those journals most frequently consulted by students of computer science, engineering, and medicine. This was done in order to ensure a representative sample of those cognates actually encountered by students in their daily reading activities. Interestingly, the researcher classified the cognates in the corpus according to some orthographical criteria namely: individual letter equivalences, position of differences, vowel/consonant groups, and part of speech. Then, students were given tests administered to evaluate their ability to recognize and interpret cognates belonging to the classes established during the analysis of the corpus. The analysis of student performance tests demonstrated that cognates were not easily recognizable on the part of those students. Thus, the researcher suggested that teachers should adopt, as a regular part of class activities, a strategy of structured and graded practice in cognate recognition.

Nagy et al. (1993) conducted a study to determine how Hispanic bilingual students' knowledge of Spanish vocabulary and ability to identify Spanish-English cognates relate to their comprehension of English expository texts. Thus, the researchers concluded that the respondents' performance on a multiple-choice test which they were given was found to be related to their ability to recognize cognate relationships. In addition, the relationship between Spanish vocabulary knowledge and English reading comprehension appeared to depend on students' ability to recognize cognates.

Likewise, De Souza (2003) investigated the relationship between cognates management and reading comprehension success. In doing so, she focused on whether cognates help in skimming a text for general comprehension and enhance prediction and recall. To this end, three different experiments were designed and applied to twenty-two ESP learners at the Extracurricular Language Courses Centre of the Federal University of 
Santa Catarina. The researcher found out that cognates do play a facilitative role in aiding learners to get the general comprehension of texts and ameliorate prediction and recall.

Otwinowska-Kasztelanic (2009) wrote a paper entitled "Raising Awareness of Cognate Vocabulary as a Strategy in Teaching English to Polish Adults". By doing so, the researcher reported on several studies which were mainly carried out on beginning and advanced Polish learners of English in order to examine and raise language awareness of cognate vocabulary. Accordingly, the researcher sought to check how awareness raising tasks change advanced students' vocabulary learning strategies, and whether they could trigger positive transfer from Polish to English, thus stressing the role of cross-linguistic similarities which is highly important for the teaching of English, the current international Lingua Franca.

In a seminal study, Talebinejad and Sarmazeh (2012) investigated false and true cognates in Persian and some Indo-European Languages like English and French. Basically, the researchers aimed at recognizing and then enumerating the false friends and true cognates of IE languages and Persian in order to be able to locate the causes of miscommunication between interlocutors. Being conducted to compare the cognate's component of Persian and some IE languages, this research was completed through document reviewing, one of qualitative research methods. Data were analyzed through descriptive analysis. For instance, the researchers identified the true cognates "name" and "nâm" in English and Persian, and "tu" and "to" (you) in French and Persian respectively. This study had several implications for foreign language teachers. Accordingly, learners' problems with false friends could be greatly reduced if teachers pay more attention to a meaningful teaching of these lexical items in context. Therefore, being aware of the true cognates or false friends facilitates communication in general and foreign language learning in particular.

Recently, Marzban and Chahardahcherik (2015) inquired into a type of cognate words called false cognates in Persian and English. These are words which have the same form in two languages but represent different meanings. The researchers tried to study and determine the historical relations between English and Persian words. It also aimed at tracing their route back from Proto Indo-European languages to the modern languages. The findings revealed that most of such problematic cognates with different meanings in Farsi and English as found through this study are likely to be confusing and deceptive for Farsi-speaking EFL learners. Their results seem to have important implications for Second/Foreign language teachers and learners. Therefore, the importance of knowledge about cognates and false cognates is brought to the fore.

Boucher, Pasquarella, Chen, and Deacon (2016) examined the development of cognate awareness and its contribution to French (second language) reading comprehension among Canadian French immersion children. Hence, Eighty-one students were tested at the end of Grade 1 and again at the end of Grade 2. Children were administered a cognate awareness task in French, in which they were asked to decide whether a French word had a cognate in English. Overall, performance on the cognate awareness task was good at both time points, and it improved overtime. Thus, for the majority of the participants, cognate awareness was evident as early as first grade. Regressions revealed that cognate awareness measured in Grades 1 and 2 made a significant contribution to Grade 2 French reading comprehension. The researchers concluded that cognate awareness is a unique aspect of second-language reading comprehension in young bilingual children.

Amini and Salehi (2017) conducted a research work which aimed at finding out whether using cognates shared in English and Laki (A language spoken in some parts of Iran) could enhance Iranian EFL learners' English vocabulary knowledge. To achieve the goal of the study, 80 EFL learners took part in the study; all of them were learning English at language institutes of Lorestan and Isfahan provinces in Iran. The participants were taught 42 English-Laki cognate words by the researcher, during six sessions. A pretest was administered before the treatment and a posttest was managed after the treatment. Findings of the study showed that cognate-based instruction is a good strategy for vocabulary learning.

\section{Methodology}

The present study depended on a well-known method for data collection. Specifically, a Translation Elicitation Task (TET) was devised and handed to a randomly chosen sample of 31 students of French at the University of Jordan during the fall semester, including 23 second year BA students, and 8 MA students (See the appendix). That was done in the hope of getting clear insights about the extent to which awareness about the existence of cognates facilitates foreign language learning in general and translation in particular.

\section{Results and Discussion}

In this section, the findings of the study are presented and discussed in three sub-sections namely: (1) Results of the Translation Elicitation Task, (2) Discussion of Results for Jordanian MA Learners of French, and (3) Discussion of 
Results for Jordanian BA Learners of French.

\subsection{Results of the Translation Elicitation Task}

As it is shown below, a frequency table and percentages were established so as to get clear insights about the extent to which MA and BA Jordanian learners of French are aware about the existence of true cognates and false cognates in the Indo-European languages: English and French. Clearly, both correct (C) and incorrect (I) responses for each category of learners were considered with a focus on cognates (items: 1, 3, 5, 6, 7, 8, 9, 10, 12, 13, 14, 15, 16,17 , and 18) and false cognates (items: $2,4,11,19$, and 20). At this juncture, it is prerequisite to mention that the number of false cognates used is less than the number of the true ones because the frequency of the former is less than the frequency of the latter across languages. Thus, Table 1 is a case in point:

Table 1. Frequencies and percentages of Jordanian learners' correct and incorrect translations of English-French true cognates and false cognates

\begin{tabular}{lcccccccccc}
\hline & \multirow{2}{*}{ Item } & \multicolumn{2}{c}{ MA $(8)$} & \multicolumn{2}{c}{ BA (23) } & \multicolumn{2}{c}{ Percentage (\%) } \\
\cline { 2 - 9 } & & $\mathrm{C}$ & $\mathrm{I}$ & $\mathrm{C}$ & $\mathrm{I}$ & $\mathrm{C}$ & $\mathrm{I}$ & $\mathrm{C}$ & $\mathrm{I}$ \\
\hline 1 & Destroy & 8 & 0 & 16 & 7 & 24 & 7 & 77.4 & 22.5 \\
2 & Introduce & 7 & 1 & 15 & 8 & 22 & 9 & 70.9 & 20.03 \\
3 & Enter & 8 & 0 & 18 & 5 & 26 & 5 & 83.8 & 16.1 \\
4 & Appear & 3 & 5 & 4 & 19 & 7 & 24 & 22.5 & 77.4 \\
5 & Colonies & 8 & 0 & 14 & 9 & 22 & 9 & 70.9 & 20.03 \\
6 & Explosion & 8 & 0 & 16 & 7 & 24 & 7 & 77.4 & 22.5 \\
7 & Invitation & 8 & 0 & 18 & 5 & 26 & 5 & 83.8 & 16.1 \\
8 & Lesson & 5 & 3 & 13 & 10 & 18 & 13 & 58.06 & 41.9 \\
9 & Extraordinary & 8 & 0 & 16 & 7 & 24 & 7 & 77.4 & 22.5 \\
10 & Fantastic & 7 & 1 & 12 & 11 & 19 & 12 & 61.2 & 38.7 \\
11 & Flexible & 0 & 8 & 0 & 23 & 0 & 31 & 0.0 & 100 \\
12 & Magic & 6 & 2 & 19 & 4 & 25 & 6 & 80.6 & 19.3 \\
13 & Nervous & 7 & 1 & 18 & 5 & 25 & 6 & 80.6 & 19.3 \\
14 & Naturally & 4 & 4 & 9 & 14 & 13 & 18 & 41.9 & 58.06 \\
15 & Absolutely & 6 & 2 & 13 & 10 & 19 & 12 & 61.2 & 38.7 \\
16 & Immediately & 5 & 3 & 12 & 11 & 17 & 14 & 54.8 & 45.16 \\
17 & Brilliant & 4 & 4 & 6 & 17 & 10 & 21 & 32.2 & 67.7 \\
18 & Curiosity & 8 & 0 & 18 & 5 & 26 & 5 & 83.8 & 13.7 \\
19 & Lecture & 6 & 2 & 12 & 11 & 18 & 13 & 58.06 & 41.9 \\
20 & Actually & 5 & 3 & 10 & 13 & 15 & 16 & 48.3 & 51.6 \\
\hline
\end{tabular}

Note. $\mathrm{C}=$ correct; $\mathrm{I}=$ incorrect.

\subsection{Discussion of Results for Jordanian MA Learners of French}

\subsubsection{Cognates}

A close examination of the data for MA Jordanian learners of French provided in table 1 postulates that the following items: destroy, enter, colonies, explosion, invitation, fantastic, magic, nervous, absolutely, extraordinary and curiosity are the cognates which the respondents belonging to this category are aware about. This is because the majority of them (ranging between 6 and 8 respondents) translated the aforementioned cognates correctly from English into French and this gave détruire, entrer, colonies, explosion, invitation, fantastique, magique, nerveux, absolument, extraordinaire and curiosité respectively. Items 8 (lesson), 14 (naturally), 16 (immediately), and 17 (brilliant), however, showed the students' relative awareness of the existence of their equivalents (cognates) in the target language (French). This line of reasoning is in conformity with the percentages of correct responses in table 1 and which are relatively low. Importantly, not a single MA Jordanian learner of French is completely not aware of the existence of cognates in English and French. For our purposes, MA students are considered to be aware of a given cognate if the number of correct reponses ranges between 8 and 6 , relatively aware if it is between 3 and 5 , and not aware if it is below 3 .

\subsubsection{False Cognates}

It is important to notice also from the outset that the Translation Elicitation Task which was used for data collection 
had 5 false cognates namely introduce, appear, flexible, lecture, and actually. Accordingly, and as it is plainly displayed in table 1, most students were completely aware of some false cognates (introduce and lecture). Yet, some respondents confused them with the French words "introduire" and "lecture" which have a totally different meaning in the sense that the former in French means "insert" while the latter stands for "reading". Hence, erroneous translations like the following were unavoidable:

囚 Introduce yourself please! $\rightarrow *$ S'il vous plait introduie. (Présentez-vous s'il vous plaît!).

冈 Tomorrow, I will give a lecture to my first year students $\rightarrow *$ Demain, je vais donner de la lecture pour les élèves du première année. (Demain, je vais donner une conférence à mes étudiants de première année). Importantly, la lecture in French means "reading".

Furthermore, items $(4,20)$ which were "appear" and "actually" respectively received a relative awareness on the part of the MA respondents in the sense that the percentages of correct responses were low ( 3 and 5). As a matter of fact, "appear" was confused with the French false cognate "apparaître" which has a variety of meanings including "to emerge, to come into existence, to spring from...etc", while "actually" was confused with its false cognate in French "actuellement" which is akin in meaning to "currently". At this juncture, it is prerequisite to state that one item: "flexible" was the most problematic one for all MA respondents in the sense that no one answered it correctly. One might suggest that this confusion could be linked to the fact that the same word exists with exactly the same spelling in both French and English. Therefore, more knowledge about the two languages is needed in order to avoid such a type of confusion. The following example clarifies the point:

$\bigotimes \quad$ Our teacher is very flexible. $\rightarrow$ *Notre professeur est très flexible (Notre professeur est très souple). The point is that, as opposed to English, we cannot say in French that a person is flexible. Rather, we use the adjective "souple".

\subsection{Discussion of Results for Jordanian BA Learners of French}

\subsubsection{Cognates}

The underlying assumption in the present research work is that cognates may facilitate the process of second language learning. This is always the case when the learners take cognizance of their existence in the languages being learned. In fact, items 3 (enter), 7 (invitation), 12 (magic) 13 (nervous), and 18 (curiosity) are no exception in the sense that the BA respondents demonstrated an excellent awareness about them and this assisted them in the translation of the sentences which they were given. Therefore, they provided the needed cognates namely: entrer, invitation, magique, and nerveux respectively. As per the relative awareness about the cognates, items 1 (destroy), 5 (colonies), 6 (explosion), 8 (lesson), 9 (extraordinary), 10 (fantastic), 15 (absolutely), and 16 (immediately) were shown to belong to this category because the frequencies of the correct answers were relatively low when compared to the items belonging to the previous category $(16,14,16,13,16,12,13$, and 12 respectively). Finally, just two items 14 (naturally), and 17 (brilliant) were problematic for BA respondents. The percentages in table 1 above are in symbiosis with this line of reasoning.

\subsubsection{False Cognates}

The nature of false cognates is that they are deceptive to learners and they seem to hinder second language learning. Interestingly, not a single informant was able to show an awareness of all the false cognates that appeared in the Translation Elicitation Task namely "introduce, appear, flexible, lecture and actually". Yet, the respondents showed some degree of relative awareness about items 2 (introduce) 19 (lecture), and 20 (actually) in that they did not confuse them with the French false cognates introduire, lecture and actuellement. Last but not least, items 11 (flexible), and 4 (appear) were really problematic for respondents in that none of them translated flexible correctly while the latter received only 4 correct responses and it was confused with the French false cognate "apparaître". Therefore, it has become crystal clear that the existing similarities in spelling between false cognates misled the learners especially those who have been learning French only for a short period of time.

In a nutshell, the foregoing discussion has brought into focus the significance of the role that cognates play in facilitating second language vocabulary learning. This is because similarities between languages often result in easiness of learning. Yet, learners must also be aware of the existence of false cognates because they harden their task of language learning. Following this line of reasoning, it is of paramount importance to state that the failure of some BA, and MA learners of French to translate some cognates and false cognates correctly could be attributed to a number of factors. These include the paucity or even the lack of instruction on the part of teachers so as to raise their awareness about the necessity of having at least a nodding acquaintance with such cognates and false cognates in French and English. At this juncture, it should be stated that our findings are in conformity with many studies that have been conducted between different languages (Moss, 1992; Nagy et al.,1993; De Souza, 2003; 
Boucher et al., 2016).

\section{Conclusion}

Our study has disclosed that the cross-linguistic phenomenon of cognates is part and parcel of second language learning, especially when the languages being considered are said to be genetically-related. Apparently, English and French-the focus of the present research work-are no exception. This is because they have a common Indo-European origin and they have been in significant contact over the course of history. Intriguingly, the results of the study highlighted the role of cognates in facilitating the process of second language vocabulary learning among Jordanian Learners of French who speak English too. Moreover, false cognates seemed to hinder the process of L2 vocabulary learning owing to their deceptive nature. Yet, it cannot be assumed that the existence of true and false cognates between languages will ensure that L2 learners will, without instruction, use or even recognize all the potential relationships between the two languages. Accordingly, foreign language instructors need to be more aware of the existence of such words and to include them in their teaching material.

Hopefully, this study, which captures neither the breadth nor the depth of the linguistic phenomenon of cognates, will pave the road for more subsequent studies about a highly important topic like the one in hand. Therefore, such studies could have as their focus other languages which belong to the same language family and could compare more items and use a larger sample of study.

Finally, we strongly recommend teachers to spend some time in training students on cognate recognition strategies. For example, instructors may provide diverse contexts for efficient cognate learning. This can be done by helping foreign language learners to read cognates in a variety of contexts including those having similar or different meanings. Therefore, reading or using cognates in different contexts may enhance building links or knowledge components needed to understand word meaning. We end by saying that cognate recognition deserves to be a part of an explicit instruction used as a strategy in foreign language learning.

\section{References}

Amini, M., \& Salehi, H. (2017). Effect of cognate-based instruction strategy on vocabulary learning among Iranian EFL learners. International Journal of Foreign Language Teaching \& Research, 5(20), 29-41.

Beltran, R. (2006). Towards a typological classification of false friends (Spanish-English). RESLA, 19, 29-39.

Boucher, K., Pasquarella, A., Chen, X., \& Deacon, H. (2016). Cognate awareness in French immersion students: Contributions to grade 2 reading comprehension. Scientific Studies of Reading, 20(5), 389-400. https://doi.org/10.1080/10888438.2016.1213265

Brown, D. (2007). Principles of Language Learning and Teaching. White Plains, MY: Pearson Education.

Burkholder, M. (2015). Les faux-amis: Investigating lexico-semantic ambiguity across two languages. Proceedings of the 2015 Annual Conference of the Canadian Linguistic Association, University of Ottawa.

De Souza, V. (2003). The role of cognates in reading comprehension: A cognitive perspective (Unpublished master's thesis). University of Federal De Santa Catrina.

Gholami, J., Alavinia, P., \& Izadpanah, S. (2015). The use of cognate words and interlingual homographs to investigate the cross-linguistics in second language processing in Iran. Sino-US English Teaching, 12(6), 448-456. https://doi.org/10.17265/1539-8072/2015.06.006

Lado, R. (1957). Linguistics across cultures. Ann Arbor: University of Michigan Press.

Marzban, A., \& Chahardahcherik, S. (2015). English and Persian cognates/pseudo cognates: A cross-linguistic investigation. International Journal of English Language and Translation Studies, 3(1), 21-34.

Moss, G. (1992). Cognate recognition: Its importance in the teaching of ESP reading courses to Spanish speakers. English for Specific Purposes, 11, 141-158. https://doi.org/10.1016/S0889-4906(05)80005-5

Nagy, W., Garcia, G., Durgunoglu, A., \& Bhatt, B. (1993). Spanish-English bilingual students' use of cognates in English reading. Journal of Reading Behavior, 25(1), 241-259. https://doi.org/10.1080/10862969009547816

Otwinowska-Kasztelanic, A. (2009). Raising Awareness of Cognate Vocabulary as a Strategy in Teaching English to Polish Adults. Innovation in Language Learning and Teaching, 3(2), 131-147. https://doi.org/10.1080/17501220802283186

Talebinejad, M., \& Sarmazeh, A. (2012). Comparative investigation of Persian's cognates and false friends with some IE language. Theory and Practice in Language Studies, 2(7), 1477-1484. https://doi.org/10.4304/tpls.2.7.1477-1484 
Walseth, H. (2013). Friend or foe: Metacognitive awareness of false friends and cognates (Unpublished master's thesis). Hamline University, Minnesota.

\section{Appendix}

\section{Section One: Personal Information}

1. Gender: Male

Female

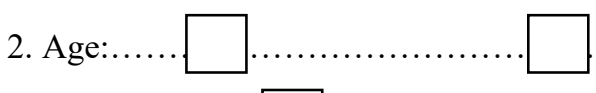

3. Level :

$\mathrm{BA}$

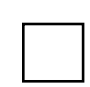

MA

4. How many years have you been learning French?

5. Where have you learned French?

Section Two: Translate the following sentences from English into French.

1. Wars destroy the world.

Les guerres détruisent le monde.

2. Introduce yourself please!

Présentez-vous s'il vous plaît!

3. The students enter the classroom at 8 p.m.

Les élèves entrent dans la classe à 8h:00.

4. The boys appear to be unhappy.

Les garçons semblent être malheureux.

5. France had many colonies in Africa.

La France avait de nombreuses colonies en Afrique.

6. I heard an explosion two days ago.

J'ai entendu une explosion il y a deux jours.

7. I received an invitation from my friend.

J'ai reçu une invitation de mon ami.

8. The lesson was difficult.

La leçon était difficile.

9. He did an extraordinary job.

Il a fait un travail extraordinaire.

10. That was fantastic.

C'était fantastique.

11. Our teacher is very flexible.

Notre professeur est très souple. 
12. That was a magic show.

C'était un spectacle magique.

13. The student was nervous after the test.

L'étudiant était nerveux après le test.

14. The topic arises naturally in the conversation.

Le sujet se pose naturellement dans la conversation.

15. It is absolutely true.

Il est absolument vrai.

16. The firemen went to the burning house immediately.

Les pompiers sont immédiatement allés à la maison en feu.

17. Marry is a brilliant student.

Marry est une brillante etudiante.

18. Curiosity killed the cat.

La curiosité a tué le chat.

19. Tomorrow, I will give a lecture to my first year students.

Demain, je vais donner une conférence à mes étudiants de première année.

20. Actually, i was absent at that day.

En fait, j'étais absent ce jour là.

\section{Copyrights}

Copyright for this article is retained by the author(s), with first publication rights granted to the journal.

This is an open-access article distributed under the terms and conditions of the Creative Commons Attribution license (http://creativecommons.org/licenses/by/4.0/). 